\title{
Correction to: Eye-body allometry across biphasic ontogeny in anuran amphibians
}

\author{
Samuel J. Shrimpton ${ }^{1,2} \cdot$ Jeffrey W. Streicher ${ }^{1} \cdot$ David J. Gower $^{1} \cdot$ Rayna C. Bell $^{3,4}$. \\ Matthew K. Fujita ${ }^{5}$. Ryan K. Schott ${ }^{4,6}$ - Kate N. Thomas ${ }^{1}$
}

Published online: 20 March 2021

(c) The Author(s) 2021

\section{Correction to: Evolutionary Ecology https://doi.org/10.1007/s10682-021-10102-3}

Figures 1 and 2 have been published incorrectly in the original publication of the article. The correct versions of the figures are provided in this correction. The original article has been corrected.

The original article can be found online at https://doi.org/10.1007/s10682-021-10102-3.

Kate N. Thomas

kate.nicole.thomas@gmail.com

1 Department of Life Sciences, The Natural History Museum, London SW7 5BD, UK

2 Division of Biosciences, University College London, London WC1E 6BT, UK

3 Department of Herpetology, California Academy of Sciences, San Francisco, CA 94118, USA

4 Department of Vertebrate Zoology, National Museum of Natural History, Smithsonian Institution, Washington, DC 20560, USA

5 Department of Biology, The University of Texas at Arlington, Arlington, TX 76019, USA

6 Department of Biology, York University, Toronto M3J 1P3, Canada 
A

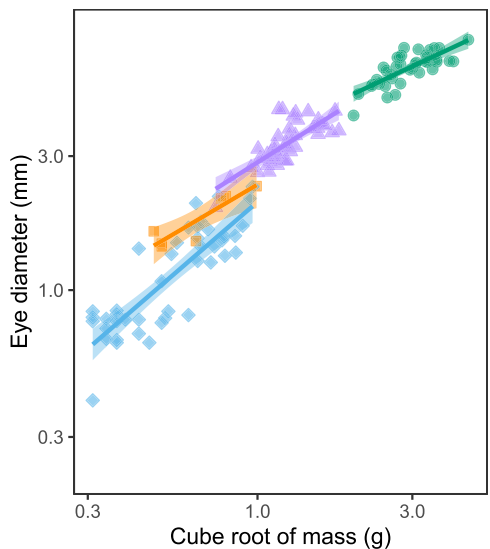

B

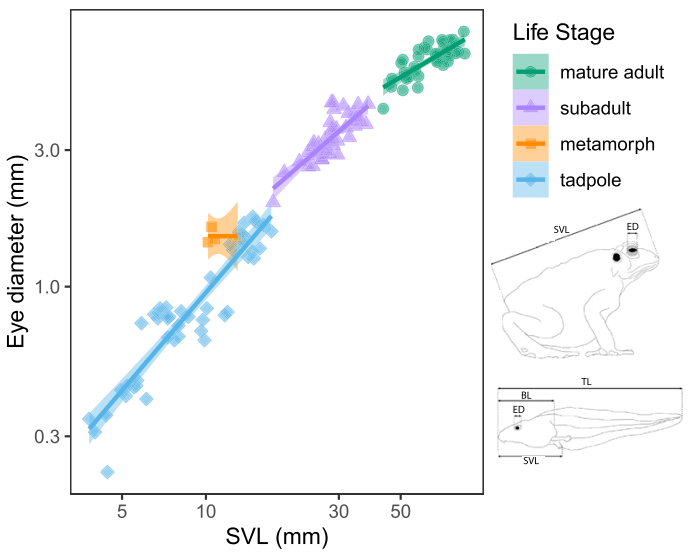

Fig. 1 Eye-body size allometry across ontogeny in the common frog, Rana temporaria. Four broad developmental stages (adult, subadult, metamorph, and tadpole) are indicated by coloration and symbol. Lines are coloured by life stage and show OLS regressions with $95 \%$ confidence intervals for $\log _{10}$ eye diameter vs. $\log _{10}$ the cube root of mass (a) or $\log _{10}$ SVL (b) for each stage. Larval illustration redrawn from Ariyasiri et al. (2011). Adult illustration redrawn from Watters et al. (2016) 

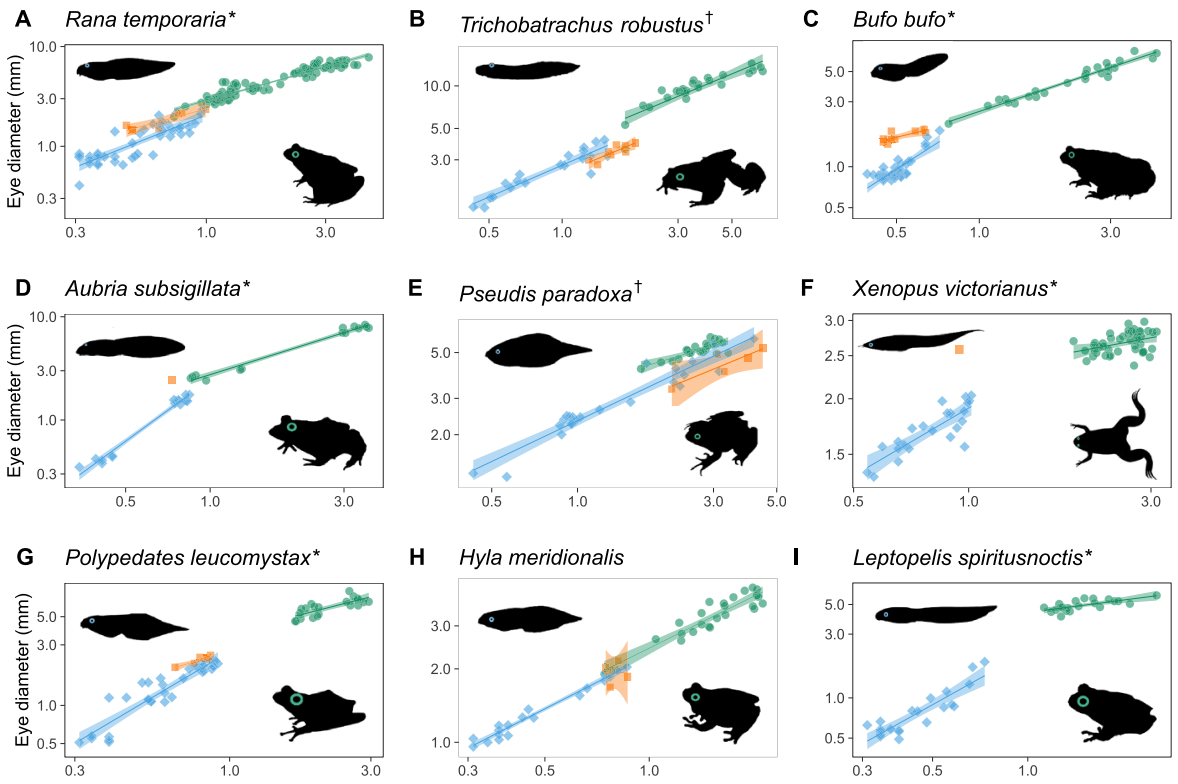

I Leptopelis spiritusnoctis*
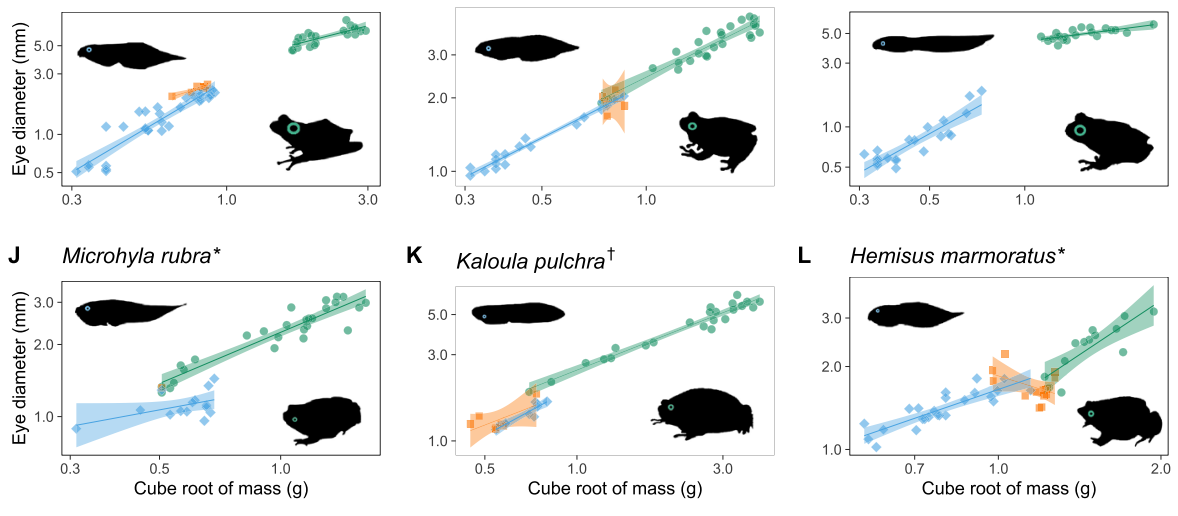

Life Stage - - adult $-m$ metamorph $-\rightarrow$ tadpole

$\mathbf{L}$ Hemisus marmoratus*

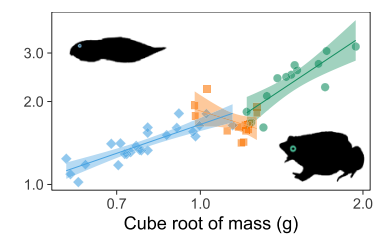

Fig. 2 Eye-body size allometry across ontogeny in 12 species of anuran amphibians: Rana temporaria (a), Trichobatrachus robustus (b), Bufo bufo (c), Aubria subsigillata (d), Pseudis paradoxa (e), Xenopus victorianus (f), Polypedates leucomystax (g), Hyla meridionalis (h), Leptopelis spiritusnoctis (i), Microhyla rubra (j), Kaloula pulchra (k), and Hemisus marmoratus (l). Three life stages (adult, metamorph, and tadpole) are indicated by colouration and symbol. Lines are coloured by life stage and indicate OLS regressions with 95\% confidence intervals for $\log _{10}$ eye diameter versus $\log _{10}$ the cube root of mass for each stage. Inset silhouettes depict the relative eye size of each species as tadpoles and adults, respectively. Asterisks indicate species with a significant difference between tadpole and adult slopes. Daggers indicate species with no significant difference between tadpole and adult slopes, but a significant difference in intercepts between life stages

Open Access This article is licensed under a Creative Commons Attribution 4.0 International License, which permits use, sharing, adaptation, distribution and reproduction in any medium or format, as long as you give appropriate credit to the original author(s) and the source, provide a link to the Creative Commons licence, and indicate if changes were made. The images or other third party material in this article are included in the article's Creative Commons licence, unless indicated otherwise in a credit line to the material. If material is not included in the article's Creative Commons licence and your intended use is not permitted by statutory regulation or exceeds the permitted use, you will need to obtain permission directly from the copyright holder. To view a copy of this licence, visit http://creativecommons.org/licenses/by/4.0/.

Publisher's Note Springer Nature remains neutral with regard to jurisdictional claims in published maps and institutional affiliations. 